\title{
Influence of Cryogenic Temperatures on Mechanical Properties of Valve Seats of Internal Combustion Engines
}

\author{
Jakub Mráz ${ }^{1}$, Břetislav Skrbek ${ }^{2}$ \\ 1 Technical University of Liberec, Faculty of Mechanical Engineering, Department of Material science, Czech Republic \\ 2 Technical University of Liberec, Faculty of Mechanical Engineering, Department of Material science, Czech Republic
}

\begin{abstract}
Valve seats of internal combustion engines are used in cylinder heads, due to increase the strength and abrasion resistance of the intake and exhaust valve seats. Valve seats are made from alloy cast iron, high-alloy steels, wear-resistant alloys and seats made using powder metallurgy. The valve seats are pressed into the head. Some materials must be deep-frozen before pressing to reduce the pressing overlap. The overlap is large, in the order of tenths of a millimetre, due to the guaranteed seating of the seat in the cylinder head. The amount of overlap depends also on the material of the cylinder head. Liquid nitrogen (about $-196{ }^{\circ} \mathrm{C}$ ) is used for freezing. In our case, these are monometallic seats, made by technology of precision casting from cobalt alloys. A particular type of cobalt alloy uses the trade name STELLITE.
\end{abstract}

Keywords: Valve seats, Young's modulus, Cobalt alloys, Stellite

\section{Introduction}

Valve seats of internal combustion engines are used in cylinder heads to increase the strength and abrasion resistance of the intake and exhaust valve seats. Seats made of high-alloy steels, wear-resistant alloys and valve seats based on powder metallurgy are used. The valve seats are pressed into the head. Some materials are deep-frozen before pressing to reduce the pressing overlap. The overlap is large, in the order of tenths of a millimetre, due to the guaranteed seating of the seat in the cylinder head. Dry ice (approx. $-80^{\circ} \mathrm{C}$ ) or liquid nitrogen (approx. $-196^{\circ} \mathrm{C}$ ) or other medium is used for freezing. In cast iron cylinder heads, valve seats can be made directly in the cylinder head. In the seat there is a conical seat (sealing) surface for the valve head at different angles - it depends on the type of the engine and its design. As a rule, this apex angle is $90^{\circ} ; 120^{\circ} ; 140^{\circ}$ this area must have a suitable width. If it is too narrow, it dissipates little heat from the valve head which can cause geometric deformation of the valve head but also deformation of the valve seat itself.

\section{Wear mechanism}

Knocking of valves is the most widespread wear of the cylinder head from the material and construction point of view. Knocking of valves can be caused by thermal deformation of the cylinder head which causes the valve to be offset against the seat - which logically leads to leakage. The misalignment may be caused by deformation of the head in the area of the valve guides or in the area of the valve seats - the seating plate of the cylinder head. The contact between valve and seat must be circular for proper operation. At the moment of line contact between valve and seat, high temperature 
combustion products penetrate between the seat and valve, causing erosive wear - the so-called. Fired valve. This type of fault is fatal to the engine. Determining the real deformations in practice using strain gauges is complicated, therefore FEM analysis is widely used. Other types of seats wear are called. GUTTERING - is a high-temperature corrosive process usually causing peeling of the surface. TORCHING is the melting of a part of the valve or valve seat that can act as an initiator of abnormal combustion. [1]

\section{Cobalt alloys used in practice}

Resistance to external deformation effects of valve seats can be expressed by the modulus of elasticity (Young's modulus). More recently, seats manufactured using powder metallurgy have been increasingly used. This technology makes it possible to combine the properties of several materials such as high wear resistance, high hardness and high thermal conductivity. The materials used vary according to engine displacement, engine speed, engine power, fuel used. One type of material used for gas engine valve seats is cobalt alloys.

Cobalt alloys with chromium, tungsten and molybdenum additives have excellent abrasion and adhesion resistance combined with high temperature and oxidation resistance. They also have a low coefficient of friction. They are used both in the form of surfacing and in the form of castings. They have high hardness and high temperature strength. The chemical composition of selected cast and wrought cobalt alloys is shown in Tab. 2.

STELLITS contains about 50\% Co, 30\% Cr, up to $4 \% \mathrm{C}$. The small additives W, Mo, Ta, Zr, Nb solidify the cobalt-based solution. $\mathrm{Mn}, \mathrm{Fe}, \mathrm{Ni}$ stabilize the FCC matrix lattice. Carbides form a eutectic in cobalt austenite. For example, Stellite 6 has a microstructure consisting of primary austenite dendrites surrounded by a carbide - austenic eutectic with a (Co, Cr) 7C3 type carbide. In Tab. 3 shows selected cobalt alloys and the effect of heat treatment on hardness. [2] [3] [4]

Stellite 6 alloys coated on stainless steel are used for valve application in a high-temperature and high-pressure environment, where a material may melt, creep, or degrade. Oxygen in air is a normal element that reacts with alloying elements, particularly at high temperatures the formation of oxides plays an important role in the wear process the alloying element $\mathrm{Cr}$ shows good wear and corrosion resistance and high-temperature strength. The wear performance of Stellite 6 alloys was relatively superior at $750{ }^{\circ} \mathrm{C}$. Oxides growing slowly on Stellite 6 alloys lead to the formation of a protective film with good wear resistance. When the surface of Stellite 6 alloy was subjected to wear, heat expansion, and oxidation, the oxide film was destroyed. The fresh surface was exposed, and oxidation was accelerated. Ultimately, the film was completely broken. This process was repeated, and the wear resistance decreased. Therefore, the bonding strength of the oxide film is a key factor affecting the total resistance at elevated temperature. [5]

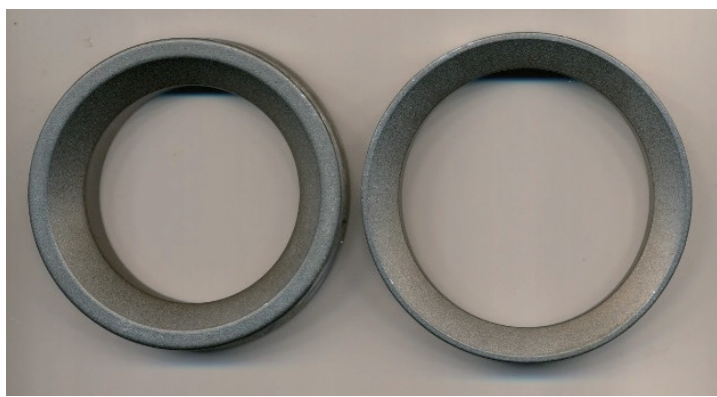

Figure 1: Exhaust and intake seats castings.

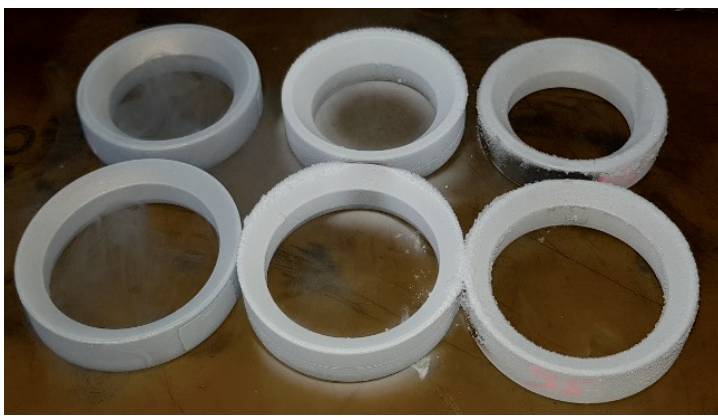

Figure 2: Valve seats after freezing.

\section{Experiment}

The aim of the experiment was to confirm or refute the effect of cryogenic temperatures on the mechanical properties of selected Stellite alloys. If the impact on mechanical properties is confirmed, the critical exposure time determined and the solution for industrial processing proposed.

The correct setting of the technological processing of Stellite alloys will help to save costs associated with unplanned maintenance, in our case internal combustion engines, which work as 
backup sources in nuclear power plants or hospitals.

The HRC hardness and sound velocity $V$ at was measured with Defectoscop DIO 562, detector calibrated to a sound speed of $5920 \mathrm{~m} / \mathrm{s}$ with a double ultrasonic probe of $10 \mathrm{MHz}, \mathrm{D}-8 \mathrm{~mm}$, which is directly proportional to the Young's modulus of elasticity $E$, were measured on the castings of the seats.

Real thickness $L$ was measuring with caliper. The measurement was repeated 5 times and an arithmetic mean was made. Residual magnetism $\mathrm{M}$ was measured on defectoscop DIO 562.

The measured values are shown in graphs $1 ; 2$ and 3, where we found the critical exposure time. Average values from 4 measurement positions on each seat were used to analyse the effect of freezing on seats stiffness expressed in $E$.

\section{Diagnostic}

Exceptionally, unacceptable wear has occurred in engines operating at high temperatures and with a unknown composition of gas. Systematic monitoring of the amount of wear, assembly and distribution of hardness $\mathrm{H}$, stiffness $\mathrm{E}$ and strength Rm (means of non-destructive structuroscopy) along the perimeter of seats brought among other things:

- A place with a significant extreme of mechanical properties is found in entering the mould cavity

- Wear $A$ in the particular type and length of valve seats operation can be predicted with high probability $(R=0,91)$ by non-destructively measured properties [1] - HRC hardness $H$ and Young's modulus Eo before fitting seats by expression (1). The Young's modulus $E$ itself (initial - measured by ultrasound) is calculated according to (2). [6] [7] [8]

$$
\begin{aligned}
& A=7,6-1,37 \times H R C \times E \times 10^{-3}[\mathrm{~mm}] \\
& E=(K \times L / L u)^{2}[\mathrm{MPa}] \\
& R_{m}=7,21 \times(L / L u)^{2,28} \times H B^{0,75}[\mathrm{MPa}] \\
& V_{L}=5920 \times L / L u[\mathrm{~m} / \mathrm{s}] \\
& K=5920 \times\left(\rho \cdot(1+\mu) \cdot \frac{(1-2 \cdot \mu)}{(1-\mu)}\right)^{1 / 2}\left[\mathrm{~s}^{2} \times \mathrm{m}^{-2} \times \mathrm{N}^{1 / 2}\right]
\end{aligned}
$$

$L[\mathrm{~mm}]$ Actual valve seat thickness

$L u[\mathrm{~mm}]$ The thickness of the seat measured by an ultrasonic thickness gauge

The dendrite thickening at the inlet should not be more than double. Measured on metallographic cut from work piece (on casting from area under machining allowance).

Curing has a favourable effect on the distribution and height of the hardness values as well as the reduction of internal stresses. Curing consists of heating with a holding time of 2 to $4 \mathrm{~h} / 900-950^{\circ} \mathrm{C}$ with cooling in the oven up to $400^{\circ} \mathrm{C}$. HRC values increase by $6 \mathrm{HRC}$ on average after $2 \mathrm{~h}$. Operational processing designed $900^{\circ} \mathrm{C}$ with $3 \mathrm{~h}$ endurance. The structure is easily etched after annealing - the annealing precipitates (fine carbides) from the solid solution are highlighted and lose ferromagnetism.

A set of machined valve seats was also measured before and after freezing. Exhaust valve seats were measured in two perpendicular directions (suppression of measurement inaccuracy) - Fig. 4. [1] [2] [4]

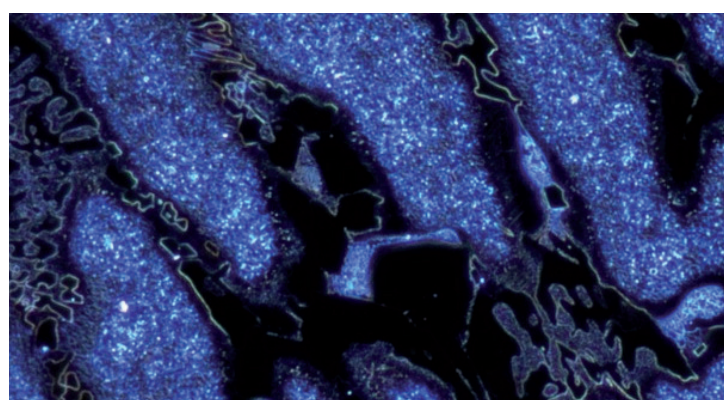

Figure 3: Stellite 6 structure after curing. Etched with VILLELA BAIN.

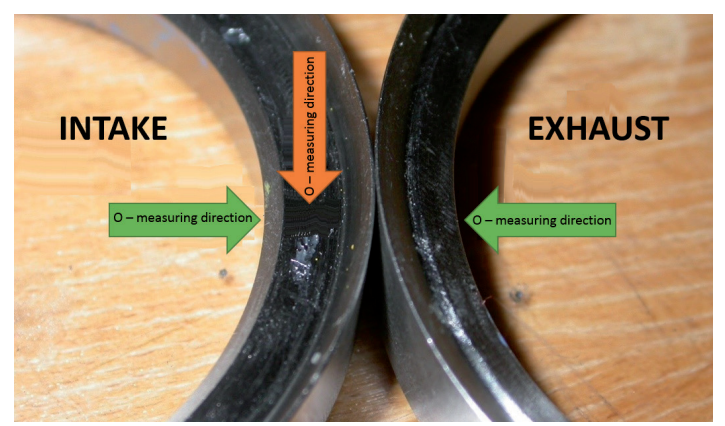

Figure 4: Direction of measuring.

The Young's modulus E (2) is equivalent to the value $V_{L}$ (4). For each material quality, it is necessary to measure and calculate the value of the constant K (5) on slim cylindrical samples. For Stellite alloys, by measuring cylindrical samples $\varnothing 12.5 \mathrm{~L} 124 \mathrm{~mm}$ and calculating the constant $\mathrm{K}$, the expression (5). $\mu$ represent the Poisson constant, Young's modulus before exposure in liquid nitrogen is labelled $E_{0}$ and after exposure to $E_{1} . \Delta E$ represents the difference in the Young's modulus before and after deposition of liquid nitrogen. 
Table 1: Measured Young's modulus before and after exposition Stellite 12 in liquid nitrogen.

\begin{tabular}{|l|l|l|l|}
\hline $\begin{array}{l}\text { Exposition time in liquid } \\
\mathrm{N}_{2}[\mathrm{~min}]\end{array}$ & $\mathrm{E}_{0}[\mathrm{GPa}]$ & $\mathrm{E}_{1}[\mathrm{GPa}]$ & $\Delta \mathrm{E}[\mathrm{GPa}]$ \\
\hline 1 & 219,1 & 222,3 & $-3,2$ \\
\hline 3 & 217,8 & 216,9 & 0,9 \\
\hline 10 & 222,6 & 219,9 & 2,7 \\
\hline 20 & 220,1 & 219,7 & 0,4 \\
\hline 60 & 216,8 & 224,7 & $-7,9$ \\
\hline 1200 & 221 & 217,4 & 3,6 \\
\hline
\end{tabular}

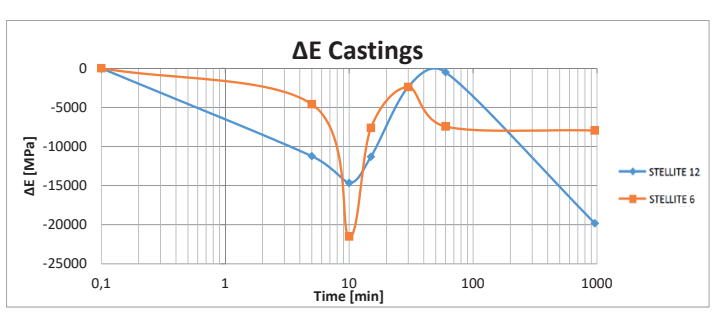

Graph 1. Change of Young's modulus on valve seats castings, due to exposure on liquid nitrogen.

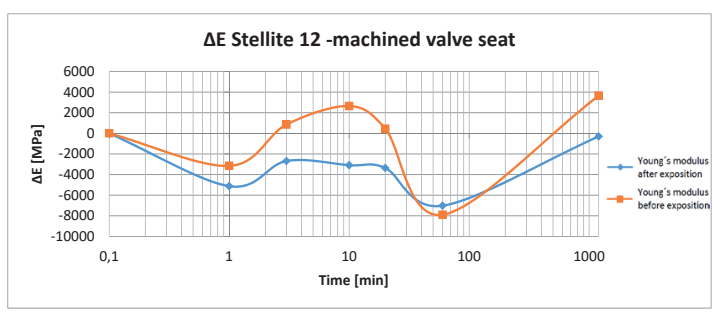

Graph 2. Change of Young's modulus on casting Ev and work piece Eo due to exposure on liquid nitrogen.

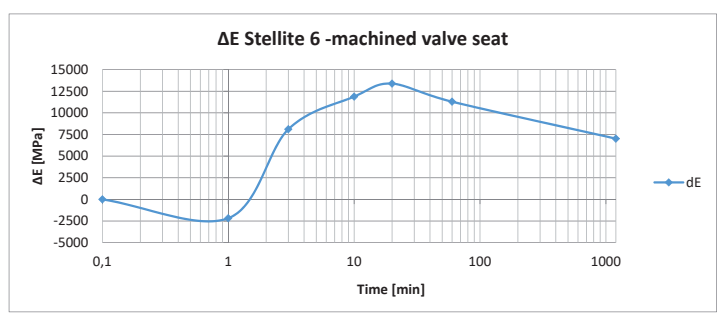

Graph 3. Change of Young's modulus on valve seats due to exposure on liquid nitrogen.

Table 2: Chemical composition of selected cobalt alloys [9].

\begin{tabular}{|c|c|c|c|c|c|c|c|c|c|c|}
\hline \multirow[t]{2}{*}{ Alloy } & \multirow[t]{2}{*}{ Condition } & \multicolumn{9}{|c|}{ Content of elements [\%] } \\
\hline & & c & $\mathrm{Mn}$ & $\mathrm{Si}$ & $\mathrm{Cr}$ & Mo & W & $\mathrm{Ni}$ & Co & Another \\
\hline Stellite 6 & Cast & $0,9-1,4$ & 1 & 1,5 & 29 & 1,5 & 4,5 & 3 & Balance & $3 \mathrm{Fe}$ \\
\hline Stellite 6B & Formed & $0,9-1,4$ & 2 & 2 & 30 & 1,5 & 4,5 & 3 & Balance & $3 \mathrm{Fe}$ \\
\hline Stellite $6 \mathrm{~K}$ & Formed & $1,4-1,9$ & 2 & 2 & 30 & 1,5 & 4,8 & 3 & Balance & $3 \mathrm{Fe}$ \\
\hline $\begin{array}{l}\text { Stellite } 6 \text { - our } \\
\text { sample }\end{array}$ & Cast & 1,1 & 0,4 & - & 29,5 & 0,8 & 4 & 3 & Balance & $\begin{array}{l}0,9 \mathrm{Al}, 3 \mathrm{Fe}, \\
0,2 \mathrm{Zr}\end{array}$ \\
\hline Stellite 12 & Cast & $1,1-1,7$ & 1 & 1 & 30 & - & 8 & 3 & Balance & $3 \mathrm{Fe}$ \\
\hline $\begin{array}{l}\text { Stellite } 12 \text { - our } \\
\text { sample }\end{array}$ & Cast & 1,2 & 0,3 & - & 30,5 & 0,5 & 10,8 & 1,6 & Balance & $\begin{array}{l}0,3 \mathrm{Fe} ; 1 \mathrm{Al} \\
0,1 \mathrm{Zr}\end{array}$ \\
\hline
\end{tabular}

Table 3: Influence of heat treatment on hardness of cobalt alloys [9].

\begin{tabular}{|l|l|l|}
\hline Alloy & Processing status & Hardness [HRC] \\
\hline \multirow{3}{*}{ Stellite 6 } & Cast & 42 \\
\cline { 2 - 3 } & Tempering $-900^{\circ} \mathrm{C} / 4$ hours / furnace & 45 \\
\hline \multirow{2}{*}{ Stellite 6B } & Tempering & 38 \\
\cline { 2 - 3 } & Cold formed - reduction - $18,5 \%$ & 47 \\
\hline Stellite 6K & Hot rolled & 44 \\
\hline Stellite 12 & Cast & 44 \\
\cline { 2 - 3 } & Tempering $-900^{\circ} \mathrm{C} / 4$ hours / furnace & 48 \\
\hline
\end{tabular}



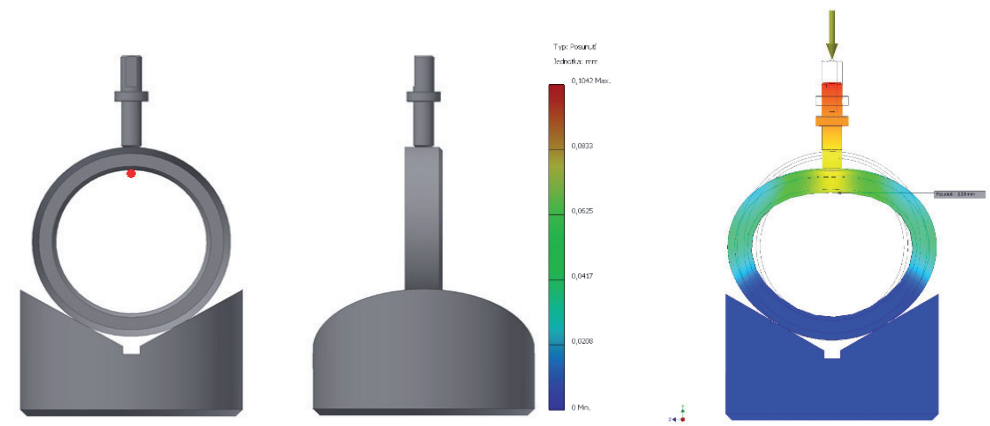

Figure 5: Method of verification of measured changes of Young's modulus by FEM analysis and modified 3-point bending.

\section{Discussion}

Measurement of the valve seat Young's modulus was carried out within the technical possibilities of the experiment. Table 1 shows the difference before and after exposure to Stellite 12 in liquid nitrogen. The table for Stellite 6 is not currently finished and is under construction as we only had valve seats to the position after exposure to nitrogen.

We are currently working on creating a mathematical model using FEM analysis and 3-point bending where we try to measure seat deflection with different exposure times in liquid nitrogen and then calculate the Young's modulus of elasticity. We use a modified indenter and calibrated load. The deflection of the valve seat is measured in the area indicated by the red dot in figure 5. The simulation results will serve to design changes of the TEDOM engine cylinder head.

Valve seats castings (Fig. 1) of cobalt alloys Stellite both exhaust and intake show a sharp extreme decrease in $E$ value at 10 min when freezing in liquid nitrogen $\left(-196^{\circ} \mathrm{C}\right)$ exposure. On the other hand, the final seats work pieces, with a substantially smaller cross-sectional area of the ring, show a local equalization of the exhaust valve seats $E$ values (freezing $\triangle \mathrm{E}$ confirmed by measuring $\mathrm{E}$ from two mutually perpendicular directions) between two minimum $\Delta E$. Intake seats with an even smaller cross section and larger diameter $D$ ring show a significant maximum increment E (about 14GPa) at 15 min exposure.

As measured, the critical time for both materials is $10 \mathrm{~min}$. Therefore, in further experiments we will focus on this peculiarity and try to figure out what changes are going to happen in the crystalline structure. Similarly, the samples are subjected to tribological tests to determine the effect of nitrogen exposure on wear and friction coefficient at low and high temperatures.

\section{Conclusion}

The Non-destructive local diagnostics of the mechanical properties components of internal combustion engines provides important design data for design models. Further research will verify the X-ray diffraction, deformation tests and findings obtained by ultrasonic measurement of valve seat stiffness. Changes in freezing $E$ are probably related to mechanical stress in the seat rings [3]. (About $14 \mathrm{GPa}$ ) at 15 min exposure.

This experiment was a pilot experiment to investigate the effect of cryogenic temperatures on the mechanical properties of cobalt alloys, which, among other things, produce valve seats. Changing the mechanical properties of valve seats due to different exposure times in liquid nitrogen will cause stiffness changes in the valve seat-cylinder head design node. Where an excessive reduction of the modulus leads to considerable deformation due to press fit. Conversely, an increase in the Young's modulus generally results in an increase in the brittleness of the material, which may cause splitting of the edges during machining.

The measured values for Stellite 6 shows:

- It is not recommended to use seats freezing technology in liquid nitrogen to reduce seat stiffness.

- The critical time is in the interval 5 - $30 \mathrm{~min}$. In this interval we measured the lowest stiffness and the lowest speed of sound.

- The recommendation for the manufacturer is to freeze valve seats from Stellite 12 material for at least 45 minutes

The measured values for Stellite 12 show:

- Paradoxically, against Stellite 6, the action of liquid nitrogen increases stiffness in specific time.

- The critical time of exposure to liquid nitrogen, where we measured the lowest stiffness and the lowest sound velocity is $10 \mathrm{~min}$.

- The recommendation for the manufacturer is to freeze valve seats 
from Stellite 12 material for at least 45 minutes.

\section{Acknowledgment}

This publication was written at the Technical University of Liberec as part project "The study and evaluation of material's structure and properties" with support of the Specific University Research Grant as provided by the Ministry of Education, Youth and Sports of the Czech Republic in the year 2020.

\section{References}

[1] LEWIS,R.,DWYER-Joyce.:Automotive Engine Valve Recesion, 2002, Wiltshire, UK, 138s. ISBN 186058358 X.

[2] BLOMBERG, R., Perrott, C. Adhesive wear processes occurring during abrasion of stellite type alloys. Journal of the Australian Institute of Metals, No. 4, p. 19, 1994.

[3] SKRBEK,B., Nosek, V. Material of valve seat. METAL 2005, pp. 22 - 26, ISBN 80-85988-38-0.

[4] SUCHÁNEK J, a kol.: Abrazivní opotřenení materiálů, 2007, Praha, 162 s. ISBN 970-80-01-03659-4

[5] ZHIYUAN Z., CHUN O., YANXIN Q., XIAOWEI Z., Wear Characteristic of Stellite 6 Alloy Hardfacing Layer by Plasma Arc Surfacing Processes, 2017, s. 1. PMID 2935905, online on: <https://www.ncbi.nlm.nih.gov/pmc/articles/ PMC5735657/>

[5] SKRBEK, B., Nosek, V. Combined nondestructive structuroscopy of dispersion metallic materials. Poster $P$ 7.16, CD, 11th European Conference on Non-Destructive Testing, CNDT, Prague 2014, ISBN 978-80-214-5019-6.

[6] YAMAMOTO, E., Motegi, R. Direct stress measurement by ultrasound. 9th WCNDT, conference proceedings, part 4E-9, Melbourne 1979.

[7] MAKOTO Kano. Highly Wear-Resistend Cast Iron for Rocker Arms-New High-Cr Cast iron Material, JSAE Rewiev, 1/1991.

[8] ŠIMÁČEK, M. PHYSICAL AND TENSILE PROPERTIES OF CAST IRON DIFFERENT IRON FOUNDRIES. Bachelor work KMT-B-093, 2004, Technical University of Liberec. 